\title{
Optimal Control Policy for a Two-Phase M/M/1 Unreliable Gated Queue under N-Policy with a Fuzzy Environment
}

\author{
Hanumantha Rao Sama ${ }^{1}$, Vasanta Kumar Vemuri ${ }^{*}$, Venkata Siva Nageswara Hari Prasad Boppana ${ }^{3}$ \\ ${ }^{1}$ Vignans Foundation for Science Technology \& Research, Division of Mathematics, Department of Sciences and Humanities, \\ Vadlamudi 522213, Guntur (Dt), Andhra Pradesh, India \\ ${ }^{2}$ Koeneru Lakshmaiah Education Foundation, Department of Mathematics, Vaddeswaram 522502, Guntur (Dt), Andhra Pradesh, \\ India \\ ${ }^{3}$ Dhanekula Institute of Engineering \&Technology, Department of Basic Sciences and Humanities, Ganguru, Vijayawada \\ 521139, Krishna (Dt), Andhra Pradesh, India
}

Corresponding Author Email: vvkumar@kluniversity.in

https://doi.org/10.18280/isi.260403

Received: 24 June 2021

Accepted: 9 August 2021

\section{Keywords:}

N-policy, two-phase, unreliable server, Zadeh's extension principle, trapezoidal fuzzy number, nonlinear programming problem

\begin{abstract}
The two-phase service models analyzed by several authors considered only the probabilistic nature of the queue parameters with fixed cost elements. But the queue parameters and cost elements will be in general are of both possibilistic and probabilistic in nature. Analyzing the performance of the queueing systems with fuzzy environment facilitates to investigate for the possibilistic interval estimates to the performance measures of a queueing system rather than point estimates. In this work, it is proposed to construct membership function of the fuzzy cost function to obtain confidence estimates for some performance measures of a controllable two-phase service single server Markovian gated queue with server startups and breakdowns under $\mathrm{N}$-policy in which the queue parameters viz. arrival rate, startup rate, batch service rate, individual service rate, repair rate and cost elements are all defined as fuzzy numbers. Based on Zadeh's extension principle and the $\alpha$-cuts, a set of parametric nonlinear programming problems are developed to find the upper and lower bounds of the minimum total expected cost per unit time at the possibility level $\alpha$. As the analytical solutions of the nonlinear programming problems developed for the proposed model are tedious, considering the system parameters and cost elements as trapezoidal fuzzy numbers, numerical results for the lower and upper bounds of the optimal threshold $\mathrm{N}^{*}$ and the minimum total expected cost per unit time are computed using the nonlinear programming solver available in MATLAB.
\end{abstract}

\section{INTRODUCTION}

Controllable operating policy is useful in several domains, including computer network management, communication systems, manufacturing, and inventory control operations. Instead, let's use an example: computer-controlled manufacturing, where raw materials are processed at the initial stage into finished products like silicon chips, bearings, and electronic components and then undergo quality checks before packaging into batches. N-policy is a well-known queue control operating policy. Under this N-policy, the server is off as soon as the system is empty and on when the waiting queue size is ' $\mathrm{N}$ '.

Yadin and Naor [1] were the first to propose the concept of N-policy. Many researchers, including Teghem [2], Lee and Srinivasan [3], Medhi and Templeton [4], Takagi [5], Wang and Hsich [6], Lee and Park [7], Hur and Paik [8], Ke [9], Tadj and $\mathrm{Ke}$ [10], Wang [11], Wang et al. [12]. Tadj and Choudhury [13], Tadj et al. [14], Wang et al. [15], and others have studied individual or batch arrival, general service, exponential or general startup, and unreliable server queueing models.

In the study of fuzzy queueing models, the basic idea is to translate a fuzzy queue to a family of conventional crisp queues by applying the $\alpha$-cut approach. Kao et al. [16] proposed a general procedure to construct the membership functions of the performance measures in queueing systems when the interarrival time and service time are fuzzy numbers. Subsequently, Chen [17] proposed a procedure for constructing the membership functions of the performance measures in finite capacity queueing system with arrival rate and service rate being fuzzy numbers in which he formulated a pair of nonlinear programs to describe the family of finite capacity queues, using the $\alpha$-cut approach. Thereafter, Lin and Ke [18] constructed the membership function of the fuzzy objective values of a controllable queueing model in which cost elements, arrival rate and service rate are fuzzy numbers. Based on the Zadeh's extension principle they developed, a set of nonlinear programs to find the upper and lower bounds of the minimal average total cost per unit time at the possibility level. Of late, Das and Baruah [19] applied the parametric programming approach to construct the membership functions of the interarrival time and service time. Bagherinejad and Pishkenari [20] proposed an FM/FM/C system based on fuzzy approach. They developed performance measures using the concept of parametric nonlinear programming and characteristics of the fuzzy numbers. Ashok Kumar [21] used the mathematical programming to construct the membership function of the system performance measures. Varadarajan 
and Susmitha [22] extended the queueing model of priority classes to the fuzzy environment by constructing the parametric programming problem where the trapezoidal fuzzy numbers are introduced for the queue parameters. Using the $\alpha$ cut approach, Kalpana and Anusheela [23] derived the membership functions of the system characteristics in nonpreemptive priority queueing model with priority subscribers in which the arrival rate and service rates are fuzzy numbers. George et al. [24] described a method to find variety of performance measures for fuzzy queueing model with an unreliable server. Aarthi et al. [25] discussed the characteristics of N-policy fuzzy queue under vague data. Vonodhini and Anitha [26] proposed a mathematical programming technique to find the membership function of the performance measures of a fuzzy single server queue in steady state.

In the process of two-phase service queueing with two services per customer, which consists of first phase batch service followed by second phase single service for all customers in the batch were initiated by Krishna and Lee [27]. Subsequently, the two-phase M/G/1 queue with N-policy was analyzed by Doshi [28]. Later, the two-phase queueing system with N-policy were explored by Kim and Chae [29]. In continuation of the above studies, the two stages $M / M / 1$ queueing system with N-policy and gating, Vasanta Kumar \& Chandan [30] presented an optimal operational policy. The detailed and performance examination of the two-phase $\mathrm{M} / \mathrm{E}_{\mathrm{k}} / 1$ and $\mathrm{M}^{\mathrm{X}} / \mathrm{M} / 1$ server breakdown and gating N-policy systems were extensively and exhaustively explored by Vasanta Kumar et al. [31, 32]. As a consequence of the above studies, batch arrival and Erlangian service two-phase controllable $\mathrm{M}^{\mathrm{X}} / \mathrm{M} / 1$ and $\mathrm{M}^{\mathrm{X}} / \mathrm{E}_{\mathrm{k}} / 1$ queueing systems with server startup and breakdowns were discussed by Vasanta Kumar et al. [33, 34]. Hari Prasad [35] presented an extensive study of Markovian server start-up queueing system with two service phases, $\mathrm{N}$ policy and an unreliable server. $\mathrm{He}$ determined the optimum threshold $\mathrm{N}^{*}$, which reduced the overall anticipated expenses per unit time, including six distinct costs. He assumed that the arrival rate, batch service rate, individual service rate, vacation rate, breakdown rate, repair rate and various cost variables are exactly known. These parameters and cost aspects cannot, however, be accurately approximated in many real-world applications. For example, the costs of maintaining a customer per unit time and the costs per unit time to keep the server in operation are more suitably described in linguistic terms high, modest, or low as well as installation costs, breakdown cost and revenue generated during secondary vacation activities. These system and cost characteristics are both possibilistic and probabilistic. There are so potentially much more practical and practical adjustable operation strategy for queueing models with fuzzy parameters than the usual crisp queues.

It has been observed from the review of literature that existing research works, including those mentioned above have not considered the controllable two-phase, N-policy Markovian queues with server breakdowns under fuzzy environment. Hence, the authors propose to consider a controllable $\mathrm{M} / \mathrm{M} / 1$ queue with two service phases and an unreliable server with a Fuzzy environment. By means of the membership functions of the system characteristics, we develop the membership functions of the minimal total expected cost using the parametric nonlinear programming approach with exponential arrival rate, batch service rate, individual service rate, startup rate, breakdown rate, repair rates and fuzzy cost elements as fuzzy numbers. Through $\alpha$ cuts and Zadeh's extension principle [36] we transform the fuzzy minimal total expected cost function into a family of crisp functions. As the nonlinear programs developed are complicated to derive the closed form solution, utilizing the nonlinear programming problem solver available in MATLAB numerical solutions are computed for assumed values of the system parameters and cost elements. These numerical solutions are helpful for the system designers and practitioners to improve the system process. The MATLAB code developed for the numerical computations is presented in APPENDIX.

\section{MODEL DESCRIPTION}

Consider a queueing system in which arrivals occur as a Poisson process with rate $\lambda$ at a single server facility; the first phase service is batch service for all customers in the queue with an exponential service rate $\beta$. After that, customers go on to the second phase of batch service, which is provided by the same server at an exponential rate $\mu$. Batch service time is independent of batch size. New Arrivals during the batch service are not permitted to join the currently running batch but are served at the server's next visit to the batch queue. This is referred to as gated service. The server returns to serve the fresh batch, if any, after completing the second phase service to all customers in the batch. Otherwise, it'll go on vacation. It will return from vacation as soon as the total number of arrivals in the queue meets or surpasses the threshold N. It takes an exponential amount of startup time with mean $1 / \theta$ before it can provide service. At a Poisson breakdown rate $\alpha$, the server can fail at any time during an individual service. When a server fails, it is dispatched to be repaired right away. Repair times are exponential with mean $1 / \gamma$. During the repair time, customers continue to arrive. In practice, we frequently seek out the best value for the control threshold $\mathrm{N}$, say $\mathrm{N}^{*}$, in order to reduce the total cost of service.

Hari Prasad [35] calculated the mean number of jobs in the system for a two-phase $\mathrm{M} / \mathrm{M} / 1$ gated queueing system with server startup, N-policy, and server breakdowns. He also formulated the total expected cost function per unit time for the system with server startup and N-policy. These findings are reported below.

The system's average number of jobs is indicated by:

$$
\begin{aligned}
& \mathrm{LN}=\frac{N(N-1)}{2\left(1-\rho_{1}\right)} P_{0,0,0}+\frac{\lambda(\lambda+N \theta)}{\theta^{2}\left(1-\rho_{1}\right)} P_{0,0,0}+\frac{\lambda}{\beta\left(1-\rho_{1}\right)} \\
& +\frac{\rho_{1}}{\left(1-\rho_{1}\right)}+\frac{\lambda \alpha \rho}{\gamma^{2}\left(1-\rho_{1}\right)}+\left(\frac{\lambda}{\beta}\right)^{2} \frac{\rho_{1}}{\left(1-\rho_{1}\right)},
\end{aligned}
$$

where,

$$
\begin{gathered}
P_{0,0,0}=\left[1-\frac{\lambda}{\mu}\left(1+\frac{\alpha}{\gamma}\right)-\frac{\lambda}{\beta}\right] \frac{\theta}{(\lambda+N \theta)}, \\
\rho=\frac{\lambda}{\mu} \text { and } \rho_{1}=\frac{\lambda}{\mu}\left(1+\frac{\alpha}{\gamma}\right)
\end{gathered}
$$

The length of the vacation period is determined by

$$
E_{0}=N / \lambda
$$


The estimated length of the startup period is determined by the formula:

$$
E_{1}=1 / \theta
$$

The estimated length of the batch service term is provided by the following formula:

$$
E_{2}=1 /\left(\beta P_{0,0,0}\right)
$$

The anticipated length of an individual's service period is indicated by:

$$
E_{3}=1 /\left(\lambda P_{0,0,0}\right)
$$

and the predicted length of the breakdown phase is determined by the following formula:

$$
E_{4}=\rho\left(\frac{\alpha}{\gamma}\right) .
$$

The duration of a busy cycle is predicted by the formula:

$$
E_{C}=E_{0}+E_{1}+E_{2}+E_{3}+E_{4}
$$

The formula for calculating the total estimated cost per unit of time is:

$$
\begin{aligned}
T(N)= & C_{h} L N+C_{o} \frac{E_{2}+E_{3}}{E_{C}}+C_{m} \frac{E_{1}}{E_{C}}+C_{b} \frac{E_{4}}{E_{C}} \\
& +C_{s} \frac{1}{E_{C}}-C_{r} \frac{E_{0}}{E_{C}},
\end{aligned}
$$

where,

$C_{h} \equiv$ Holding cost per customer in the system;

$C_{o} \equiv$ Running and maintained costs per time unit;

$C_{m} \equiv$ Costs associated with the startup of each unit of time per cycle;

$C_{s} \equiv$ Cost of setup each busy cycle;

$C_{b} \equiv$ Cost breakdown for the unreliable server on a perunit-time basis and,

$C_{r} \equiv$ reward per unit time due to secondary work during vacation.

The total expected cost minimization problem in Eq. (4) can be illustrated mathematically as:

$$
\begin{gathered}
\psi\left(\lambda, \beta, \mu, \theta, \delta, \gamma, C_{h}, C_{0}, C_{m}, C_{s}, C_{b}, C_{r}\right) \\
=\min _{N>0}\left\{\begin{array}{l}
C_{h} L N+C_{0}\left(\frac{E_{2}+E_{3}}{E_{C}}\right)+C_{m}\left(\frac{E_{1}}{E_{C}}\right)+C_{b}\left(\frac{E_{4}}{E_{C}}\right) \\
+C_{b}\left(\frac{1}{E_{C}}\right)-C_{r}\left(\frac{E_{0}}{E_{C}}\right)
\end{array}\right\}
\end{gathered}
$$

Assume that the arrival rate $\lambda$, batch service rate $\beta$, individual service rate $\mu$, startup rate $\theta$, breakdown rate $\delta$, repair rate $\gamma$, holding cost $C_{h}$, operating cost $C_{o}$, startup cost $C_{m}$, setup cost $C_{s}$, breakdown cost $C_{b}$ and reward $C_{r}$ are approximately known and can be represented by the fuzzy sets $\tilde{\lambda}, \tilde{\beta}, \tilde{\mu}, \tilde{\theta}, \tilde{\delta}, \tilde{\gamma}, \tilde{C}_{h}, \tilde{C}_{0}, \tilde{C}_{m}, \tilde{C}_{s}, \tilde{C}_{b}$ and $\tilde{\mathrm{C}}_{\mathrm{r}}$ respectively.

$$
\text { Let } \begin{array}{lll} 
& \xi_{\tilde{\lambda}}(a), \xi_{\tilde{\beta}}(b), \xi_{\tilde{\mu}}(c), \xi_{\tilde{\theta}}(d), \xi_{\tilde{\delta}}(e), \xi_{\tilde{\gamma}}(f), & \\
& \xi_{\tilde{C}_{h}}(g), \xi_{\tilde{C}_{o}}(h), \xi_{\tilde{C}_{m}}(i), \xi_{\tilde{C}_{s}}(j), \xi_{\tilde{C}_{b}}(k) & \text { and }
\end{array}
$$

$\xi_{\tilde{C}_{r}}(l)$ denote the membership functions of $\tilde{\lambda}, \tilde{\beta}, \tilde{\mu}, \tilde{\theta}, \tilde{\delta}, \tilde{\gamma}, \tilde{\mathrm{C}}_{\mathrm{h}}, \tilde{\mathrm{C}}_{0}, \tilde{\mathrm{C}}_{m}, \tilde{\mathrm{C}}_{\mathrm{s}}, \tilde{C}_{b}$ and $\tilde{\mathrm{C}}_{\mathrm{r}}$ respectively. Then the corresponding fuzzy sets are given below:

$$
\begin{aligned}
& \tilde{\lambda}=\left\{\left(a, \xi_{\tilde{\lambda}}(a)\right): a \in A\right\}, \\
& \tilde{\beta}=\left\{\left(b, \xi_{\tilde{\beta}}(b)\right): b \in B\right\},
\end{aligned}
$$

$$
\begin{gathered}
\tilde{\mu}=\left\{\left(c, \xi_{\tilde{\mu}}(c)\right): c \in C\right\}, \\
\tilde{\theta}=\left\{\left(d, \xi_{\tilde{\theta}}(d)\right): d \in D\right\}, \\
\tilde{\delta}=\left\{\left(e, \xi_{\tilde{\delta}}(e)\right): e \in E\right\}, \\
\tilde{\gamma}=\left\{\left(f, \xi_{\tilde{\gamma}}(f)\right): f \in F\right\}, \\
\tilde{C}_{h}=\left\{\left(g, \xi_{\tilde{C}_{h}}(g)\right): g \in G\right\}, \\
\tilde{C}_{o}=\left\{\left(h, \xi_{\tilde{C}_{0}}(h)\right): h \in H\right\}, \\
\tilde{C}_{r}=\left\{\left(l, \xi_{\tilde{C}_{r}}(l)\right): l \in L\right\}, \\
\tilde{C}_{m}=\left\{\left(i, \xi_{\tilde{C}_{m}}(i)\right): i \in I\right\}, \\
\tilde{C}_{s}=\left\{\left(j, \xi_{\tilde{C}_{s}}(j)\right): j \in J\right\},
\end{gathered}
$$

where, $A, B, C, D, E, F, G, H, I, J, K$ and $L$ are the crisp universal sets of the arrival rate, batch service rate, individual service rate, startup rate, breakdown rate, repair rate, holding cost, operating cost, startup cost, setup cost, breakdown cost and reward respectively. 
The membership function of the total cost minimization function $\quad \tilde{\psi}\left(\tilde{\lambda}, \tilde{\beta}, \tilde{\mu}, \tilde{\theta}, \tilde{\delta}, \tilde{\gamma}, \tilde{C}_{h}, \tilde{C}_{0}, \tilde{C}_{m}, \tilde{C}_{s}, \tilde{C}_{b}, \tilde{C}_{r}\right)$ from Eq. (5) is defined as follows, in accordance with Zadeh's extension principle:

$$
\begin{aligned}
& \xi_{\tilde{\psi}\left(\tilde{\lambda}, \tilde{\beta}, \tilde{\mu}, \tilde{\theta}, \tilde{\delta}, \tilde{\gamma}, \tilde{C}_{h}, \tilde{C}_{0}, \tilde{C}_{m}, \tilde{C}_{s}, \tilde{C}_{b}, \tilde{C}_{r}\right)}(z) \\
& =\sup _{a \in A, b \in B, c \in C, d \in D, e \in E, f \in F,} \min _{z=\phi(a, b, c, d, e, f, g, h, i, j, k, l)} \\
& g \in G, h \in H, i \in I, j \in J, k \in K, l \in L \\
& \left\{\xi_{\tilde{\lambda}}(a), \xi_{\tilde{\beta}}(b), \xi_{\tilde{\mu}}(c), \xi_{\tilde{\theta}}(d), \xi_{\tilde{\delta}}(e), \xi_{\tilde{\gamma}}(f),\right. \\
& \left.\xi_{\tilde{C}_{h}}(g), \xi_{\tilde{C}_{o}}(h), \xi_{\tilde{C}_{m}}(i), \xi_{\tilde{C}_{s}}(j), \xi_{\tilde{C}_{b}}(k), \xi_{\tilde{C}_{r}}(l)\right\}
\end{aligned}
$$

where,

$$
\begin{aligned}
& \psi(a, b, c, d, e, f, g, h, i, j, k, l) \\
& =\min _{N>0}\left\{\left[\begin{array}{l}
\left(\frac{N(N-1)}{2\left(1-\rho_{1}\right)}+\frac{a N(a+N d)}{d^{2}\left(1-\rho_{1}\right)}\right) P_{0,0,0} \\
+\frac{a}{b\left(1-\rho_{1}\right)}+\frac{\rho_{1}}{\left(1-\rho_{1}\right)}+\frac{a e \rho}{f^{2}\left(1-\rho_{1}\right)}+\left(\frac{a}{b}\right)^{2} \frac{\rho_{1}}{\left(1-\rho_{1}\right)}
\end{array}\right]\right.
\end{aligned}
$$

where,

$$
\begin{aligned}
& P_{0,0,0}=\left[1-\frac{a}{c}\left(1+\frac{e}{f}\right)-\frac{a}{b}\right] \frac{d}{(a+N D)}, \\
& \rho=\frac{a}{c} \text { and } \rho_{1}=\frac{a}{c}\left(1+\frac{e}{f}\right)
\end{aligned}
$$

Clearly, the total minimum cost per unit time $\tilde{\psi}$ is not a crisp number but a fuzzy number.

\section{PARAMETRIC NON-LINEAR PROGRAMMING APPROACH}

The $\alpha$-cuts of $\tilde{\lambda}, \tilde{\beta}, \tilde{\mu}, \tilde{\theta}, \tilde{\delta}, \tilde{\gamma}, \tilde{\mathrm{C}}_{\mathrm{h}}, \tilde{\mathrm{C}}_{0}, \tilde{\mathrm{C}}_{m}, \tilde{\mathrm{C}}_{\mathrm{s}}, \tilde{C}_{b}$ and $\tilde{\mathrm{C}}_{\mathrm{r}}$ can be defined by:

$$
\begin{gathered}
\lambda(\alpha)=\left[a_{\alpha}^{L}, a_{\alpha}^{U}\right]=\left[\min _{a \in A}\left\{a: \xi_{\tilde{\lambda}}(a) \geq \alpha\right\}, \max _{a \in A}\left\{a: \xi_{\tilde{\lambda}}(a) \geq \alpha\right\}\right] \\
\beta(\alpha)=\left[b_{\alpha}^{L}, b_{\alpha}^{U}\right]=\left[\min _{b \in B}\left\{b: \xi_{\tilde{\beta}}(b) \geq \alpha\right\}, \max _{b \in B}\left\{b: \xi_{\tilde{\beta}}(b) \geq \alpha\right\}\right] \\
\mu(\alpha)=\left[c^{L}, c_{\alpha}^{U}\right]=\left[\min _{c \in C}\left\{c: \xi_{\tilde{\mu}}(c) \geq \alpha\right\}, \max _{c \in C}\left\{c: \xi_{\tilde{\mu}}(c) \geq \alpha\right\}\right] \\
\theta(\alpha)=\left[d^{L},{ }_{\alpha}^{U}, \begin{array}{c}
U \\
\alpha
\end{array}\right]=\left[\min _{d \in D}\left\{d: \xi_{\tilde{\theta}}(d) \geq \alpha\right\}, \max _{d \in D}\left\{d: \xi_{\tilde{\theta}}(d) \geq \alpha\right\}\right] \\
\delta(\alpha)=\left[\begin{array}{c}
e^{L}, e \\
\alpha
\end{array}\right]=\left[\min _{e \in E}\left\{e: \xi_{\tilde{\delta}}(e) \geq \alpha\right\}, \max _{e \in E}\left\{e: \xi_{\tilde{\delta}}(e) \geq \alpha\right\}\right]
\end{gathered}
$$

$$
\begin{gathered}
\gamma(\alpha)=\left[f \frac{L}{\alpha}, f \begin{array}{l}
U \\
\alpha
\end{array}\right]=\left[\min _{f \in F}\left\{f: \xi_{\tilde{\gamma}}(f) \geq \alpha\right\}, \max _{f \in F}\left\{f: \xi_{\tilde{\gamma}}(f) \geq \alpha\right\}\right] \\
C_{h}(\alpha)=\left[{ }_{g}^{L}, g_{\alpha}^{U} \alpha\right]=\left[\min _{g \in G}\left\{g: \xi_{\tilde{C}}(g) \geq \alpha\right\}, \max _{g \in G}\left\{g: \xi_{\tilde{C}_{h}}(g) \geq \alpha\right\}\right]
\end{gathered}
$$$$
C_{o}(\alpha)=\left[h_{\alpha}^{L}, h_{\alpha}^{U}\right]=\left[\min _{h \in H}\left\{h: \xi_{\tilde{C}_{o}}(h) \geq \alpha\right\}, \max _{h \in H}\left\{h: \xi_{\tilde{C}_{o}}(h) \geq \alpha\right\}\right]
$$$$
C_{m}(\alpha)=\left[{ }_{i}^{L}, i_{\alpha}^{U}\right]=\left[\min _{i \in I}\left\{i: \xi_{\tilde{C}_{m}}(i) \geq \alpha\right\}, \max _{i \in I}\left\{i: \xi_{\tilde{C}_{m}}(i) \geq \alpha\right\}\right]
$$$$
C_{s}(\alpha)=\left[j_{\alpha}^{L}, j_{\alpha}^{U}\right]=\left[\min _{j \in J}\left\{j: \xi_{\tilde{C}_{s}}(j) \geq \alpha\right\}, \max _{j \in J}\left\{j: \xi_{\tilde{C}_{s}}(j) \geq \alpha\right\}\right]
$$

$$
\begin{aligned}
& C_{b}(\alpha)=\left[k{ }_{\alpha}^{L}, k{ }_{\alpha}^{U}\right]=\left[\min _{k \in K}\left\{k: \xi_{\tilde{C}_{b}}(k) \geq \alpha\right\}, \max _{k \in K}\left\{k: \xi_{\tilde{C}_{b}}(k) \geq \alpha\right\}\right] \\
& C_{r}(\alpha)=\left[l^{L}, l_{\alpha}^{U}\right]=\left[\min _{l \in L}\left\{l: \xi_{\tilde{C}_{r}}(l) \geq \alpha\right\}, \max _{l \in L}\left\{l: \xi_{\tilde{C}_{r}}(l) \geq \alpha\right\}\right]
\end{aligned}
$$

The queue parameters and cost elements are shown as intervals when the membership functions are not less than a given possibility level $\alpha$.

$$
\begin{gathered}
\text { Let } H(a, b, c, d, e, f, g, h, i, j, k, l) \\
=g\left[\begin{array}{l}
\left(\frac{N(N-1)}{2\left(1-\rho_{1}\right)}+\frac{a N(a+N d)}{d^{2}\left(1-\rho_{1}\right)}\right) P_{0,0,0} \\
\left.+\frac{a}{b\left(1-\rho_{1}\right)}+\frac{\rho_{1}}{\left(1-\rho_{1}\right)}+\frac{a e \rho}{f^{2}\left(1-\rho_{1}\right)}+\left(\frac{a}{b}\right)^{2} \frac{\rho_{1}}{\left(1-\rho_{1}\right)}\right] \\
+h\left(\frac{a}{b}+\rho\right)+i\left(\frac{a}{d} P_{0,0,0}\right)+j\left(a P_{0,0,0}\right)+k\left(\frac{\rho e}{f}\right)-l\left(N P_{0,0,0}\right)
\end{array}\right.
\end{gathered}
$$

The lower and upper bounds of the $\alpha$-cuts of $\xi_{\tilde{\psi}}(z)$ are:

$$
\psi_{\alpha}^{L}=\min _{a, b, c, d, e, f, g, h, i, j, k, l \in R^{+}} \min _{N>0} H(a, b, c, d, e, f, g, h, i, j, k, l)
$$

such that

$a_{\alpha}^{L} \leq a \leq a_{\alpha}^{U}, b_{\alpha}^{L} \leq b \leq b_{\alpha}^{U}, c_{\alpha}^{L} \leq c \leq c_{\alpha}^{U}, d_{\alpha}^{L} \leq d \leq d_{\alpha}^{U}$, $e_{\alpha}^{L} \leq e \leq e_{\alpha}^{U}, \quad f_{\alpha}^{L} \leq f \leq f_{\alpha}^{U}, \quad g_{\alpha}^{L} \leq g \leq g_{\alpha}^{U}$, $h_{\alpha}^{L} \leq h \leq h_{\alpha}^{U}, i_{\alpha}^{L} \leq i \leq i_{\alpha}^{U}, \quad j_{\alpha}^{L} \leq j \leq j_{\alpha}^{U}, \quad k_{\alpha}^{L} \leq k \leq k_{\alpha}^{U}$, $l_{\alpha}^{L} \leq l \leq l_{\alpha}^{U}$.

$$
\psi_{\alpha}^{U}=\max _{a, b, c, d, e, f, g, h, i, j, k, l \in R^{+}} \min _{N>0} H(a, b, c, d, e, f, g, h, i, j, k, l)
$$

such that

$a_{\alpha}^{L} \leq a \leq a_{\alpha}^{U}, b_{\alpha}^{L} \leq b \leq b_{\alpha}^{U}, c_{\alpha}^{L} \leq c \leq c_{\alpha}^{U}, d_{\alpha}^{L} \leq d \leq d_{\alpha}^{U}$, $e_{\alpha}^{L} \leq e \leq e_{\alpha}^{U}, \quad f_{\alpha}^{L} \leq f \leq f_{\alpha}^{U}, \quad g_{\alpha}^{L} \leq g \leq g_{\alpha}^{U}$, $h_{\alpha}^{L} \leq h \leq h_{\alpha}^{U}, \quad i_{\alpha}^{L} \leq i \leq i_{\alpha}^{U}, \quad j_{\alpha}^{L} \leq j \leq j_{\alpha}^{U}, \quad k_{\alpha}^{L} \leq k \leq k_{\alpha}^{U}$, $l_{\alpha}^{L} \leq l \leq l_{\alpha}^{U}$. 
Since Eq. 11(a) is to find the minimum of all the minimum objective values, the two-level mathematical programming problem can be simplified to the following one level mathematical programming problem.

$$
\psi_{\alpha}^{L}=\min _{N>0} T(N, a, b, c, d, e, f, g, h, i, j, k, l)
$$

such that

$a_{\alpha}^{L} \leq a \leq a_{\alpha}^{U}, b_{\alpha}^{L} \leq b \leq b_{\alpha}^{U}, c_{\alpha}^{L} \leq c \leq c_{\alpha}^{U}, d_{\alpha}^{L} \leq d \leq d_{\alpha}^{U}$, $e_{\alpha}^{L} \leq e \leq e_{\alpha}^{U}, \quad f_{\alpha}^{L} \leq f \leq f_{\alpha}^{U}, \quad g_{\alpha}^{L} \leq g \leq g_{\alpha}^{U}$, $h_{\alpha}^{L} \leq h \leq h_{\alpha}^{U}, \quad i_{\alpha}^{L} \leq i \leq i_{\alpha}^{U}, \quad j_{\alpha}^{L} \leq j \leq j_{\alpha}^{U}, \quad k_{\alpha}^{L} \leq k \leq k_{\alpha}^{U}$, $l_{\alpha}^{L} \leq l \leq l_{\alpha}^{U}$.

To solve $11(\mathrm{~b})$, we treat the inner $\min _{N}$ problem, in that $a, b, c, d, e, f, g, h, i, j, k, l$ could be viewed as constants. The only unknown in the objective function of the inner $\min _{N}$ problem is $N$.

$$
\text { Let } T(N ; a, b, c, d, e, f, g, h, i, j, k, l) \triangleq G(N)
$$

Then the inner $\min _{N}$ problem of Eq. 11(b) becomes $\min G(N)$, which is a local minimization problem. From the second derivative test, if $G^{\prime}\left(N_{0}\right)=0$ and $G^{\prime \prime}\left(N_{0}\right)>0$ then $G(N)$ has a local minimum at $N=N_{0}$. Hence, Eq 11(b) can be reformulated as the following mathematical programming problem.

$$
\psi_{\alpha}^{U}=\min _{N_{0}>0} G(N)
$$

such that

$a_{\alpha}^{L} \leq a \leq a_{\alpha}^{U}, b_{\alpha}^{L} \leq b \leq b_{\alpha}^{U}, c_{\alpha}^{L} \leq c \leq c_{\alpha}^{U}, d_{\alpha}^{L} \leq d \leq d_{\alpha}^{U}$, $e_{\alpha}^{L} \leq e \leq e_{\alpha}^{U}, \quad f_{\alpha}^{L} \leq f \leq f_{\alpha}^{U}, \quad g_{\alpha}^{L} \leq g \leq g_{\alpha}^{U}$, $h_{\alpha}^{L} \leq h \leq h_{\alpha}^{U}, \quad i_{\alpha}^{L} \leq i \leq i_{\alpha}^{U}, \quad j_{\alpha}^{L} \leq j \leq j_{\alpha}^{U}, \quad k_{\alpha}^{L} \leq k \leq k_{\alpha}^{U}$, $l_{\alpha}^{L} \leq l \leq l_{\alpha}^{U}$.

At least one $a, b, c, d, e, f, g, h, i, j, k$ and $l$ must hit the boundary of their $\alpha$-cuts to satisfy $\xi_{\tilde{\psi}}=\alpha$.

The lower bound $\psi_{\alpha}^{L}$ and upper bound $\psi_{\alpha}^{U}$ of the $\alpha$-cuts of $\tilde{\psi}$ can be found by solving Eqns. (12) and (14), respectively.

\section{NUMERICAL EXAMPLE}

We obtain the numerical solution of the crisp intervals $\left[\psi_{\alpha}^{L}, \psi_{\alpha}^{U}\right], 0 \leq \alpha \leq 1$. The values taken in this example are assumed to be mathematically reasonable and viable. No specific realistic cases are taken into account. However, under the assumption that, the arrival rate, batch service rate, individual service rate, startup rate, breakdown rate, repair rate, holding cost, operating cost, startup cost, setup cost, breakdown cost and reward are trapezoidal fuzzy numbers, and they are represented by:

$\tilde{\lambda}=[2,3,4,5], \quad \tilde{\beta}=[10,11,12,13], \tilde{\mu}=[8,9,10,11], \quad \tilde{\theta}=$ $[3,4,5,6], \tilde{\delta}=[0.2,0.3,0.4,0.5], \tilde{\gamma}=[3,4,5,6], \tilde{C}_{h}=[5,6,7$, $8], \widetilde{C}_{o}=[10,15,20,25], \tilde{C}_{m}=[100,150,200,250], \tilde{C}_{s}=[200$, $250,300,350], \tilde{C}_{b}=[50,60,70,80]$, and $\tilde{C}_{r}=[30,40,50$, $60]$ respectively.

Then the $\alpha$-cuts of the system parameters and cost elements are:

$$
\begin{gathered}
{\left[a_{\alpha}^{L}, a_{\alpha}^{U}\right]=[2+\alpha, 5-\alpha],\left[b_{\alpha}^{L}, b_{\alpha}^{U}\right]=[10+\alpha, 13-\alpha],} \\
{\left[c_{\alpha}^{L}, c_{\alpha}^{U}\right]=[8+\alpha, 11-\alpha],\left[d_{\alpha}^{L}, d_{\alpha}^{U}\right]=[3+\alpha, 6-\alpha],} \\
{\left[e_{\alpha}^{L}, e_{\alpha}^{U}\right]=[0.2+0.1 \alpha, 0.5-0.1 \alpha],\left[f_{\alpha}^{L}, f_{\alpha}^{U}\right]=[3+\alpha, 6-\alpha],} \\
{\left[g_{\alpha}^{L}, g_{\alpha}^{U}\right]=[5+\alpha, 8-\alpha],\left[h_{\alpha}^{L}, h_{\alpha}^{U}\right]=[10+5 \alpha, 25-5 \alpha],} \\
{\left[i_{\alpha}^{L}, i_{\alpha}^{U}\right]=[100+50 \alpha, 250-50 \alpha],} \\
{\left[j_{\alpha}^{L}, j_{\alpha}^{U}\right]=[200+50 \alpha, 350-50 \alpha],} \\
{\left[k_{\alpha}^{L}, k_{\alpha}^{U}\right]=[50+10 \alpha, 80-10 \alpha],} \\
{\left[l_{\alpha}^{L}, l_{\alpha}^{U}\right]=[30+10 \alpha, 60-10 \alpha] .}
\end{gathered}
$$

The minimum point $N_{0}$ such that $G^{\prime}\left(N_{0}\right)=0$ and $G^{\prime \prime}\left(N_{0}\right)>0$ is given by:

$$
N_{0}=-\sigma+\sqrt{\sigma(\sigma+1)+\frac{2 \sigma\left(1-\rho_{1}\right)}{g}(i+d j+l)}
$$

And

$$
G^{\prime \prime}\left(N_{0}\right)=\frac{a d\left(1-\rho_{2}\right)}{\left(1-\rho_{1}\right)(a+N d)^{3}}\left[g(a+d)+d\left(1-\rho_{1}\right)(i+d j+l)\right]
$$

where, $\sigma=\frac{a}{d}, \rho_{1}=\frac{a}{c}\left(1+\frac{e}{f}\right)$ and $\rho_{2}=\frac{a}{c}\left(1+\frac{e}{f}\right)+\frac{a}{b}$.

From the Eqns. (12) and (14), the membership function of $\tilde{\psi}$ can be formulated as

$$
\psi_{\alpha}^{L}=\min H(N)
$$

such that

$$
\begin{aligned}
& \frac{a d\left(1-\rho_{2}\right)}{\left(1-\rho_{1}\right)(a+N d)^{3}}\left[g(a+d)+d\left(1-\rho_{1}\right)(i+d j+l)\right]>0, \\
& 2+\alpha \leq a \leq 5-\alpha, 10+\alpha \leq b \leq 13-\alpha, 8+\alpha \leq c \leq 11-\alpha, \\
& 3+\alpha \leq d \leq 6-\alpha, 0.2+0.1 \alpha \leq e \leq 0.5-0.1 \alpha, \\
& 3+\alpha \leq f \leq 6-\alpha, 5+\alpha \leq g \leq 8-\alpha, \\
& 10+5 \alpha \leq h \leq 25-5 \alpha, 100+50 \alpha \leq i \leq 250-50 \alpha, \\
& 200+5 \alpha \leq j \leq 350-50 \alpha, 50+10 \alpha \leq k \leq 80-10 \alpha, \\
& 30+10 \alpha \leq l \leq 60-10 \alpha .
\end{aligned}
$$

$$
\psi_{\alpha}^{U}=\max H\left(N_{0}\right)
$$


such that

$N_{0}=-\sigma+\sqrt{\sigma(\sigma+1)+\frac{2 \sigma\left(1-\rho_{1}\right)}{g}(i+d j+l)}$,

$2+\alpha \leq a \leq 5-\alpha, 10+\alpha \leq b \leq 13-\alpha, 8+\alpha \leq c \leq 11-\alpha$,

$3+\alpha \leq d \leq 6-\alpha, 0.2+0.1 \alpha \leq e \leq 0.5-0.1 \alpha$,

$3+\alpha \leq f \leq 6-\alpha, 5+\alpha \leq g \leq 8-\alpha, 10+5 \alpha \leq h \leq 25-5 \alpha$,

$100+50 \alpha \leq i \leq 250-50 \alpha, 200+5 \alpha \leq j \leq 350-50 \alpha$,

$50+10 \alpha \leq k \leq 80-10 \alpha, 30+10 \alpha \leq l \leq 60-10 \alpha$.

Table 1. The $\alpha$-cuts of optimal threshold $\left(\mathrm{N}^{*}\right)$, lower and upper bounds of the minimal total estimated cost per unit time $(\psi)$ at different possibility level $\alpha$

\begin{tabular}{lllcc}
\hline $\boldsymbol{\alpha}$ & $\left(\boldsymbol{N}^{*}\right)^{\boldsymbol{L}}$ & $\left(\boldsymbol{N}^{*}\right)^{\boldsymbol{U}}$ & $\boldsymbol{\psi}^{\boldsymbol{L}}$ & $\boldsymbol{\psi}^{\boldsymbol{U}}$ \\
\hline 0.0 & 5.83 & 9.98 & 31.18 & 44.38 \\
0.1 & 6.03 & 9.93 & 33.37 & 45.00 \\
0.2 & 6.24 & 9.88 & 35.39 & 45.55 \\
0.3 & 6.44 & 9.82 & 37.25 & 46.02 \\
0.4 & 6.65 & 9.76 & 38.96 & 46.43 \\
0.5 & 6.85 & 9.70 & 40.61 & 46.77 \\
0.6 & 7.12 & 9.64 & 42.70 & 47.03 \\
0.7 & 7.27 & 9.58 & 43.84 & 47.24 \\
0.8 & 7.50 & 9.51 & 44.85 & 47.37 \\
0.9 & 7.69 & 9.44 & 45.37 & 47.44 \\
1.0 & 7.91 & 9.37 & 46.26 & 47.53 \\
\hline
\end{tabular}

From Table 1, we can notice that the range of the optimal threshold at $\alpha=1$ is [7.91,9.37], which are most possible values of the threshold $N^{*}$. Further the range of the threshold $N^{*}$ at $\alpha$ $=0$ is $[5.83,9.98]$, which indicates that the threshold $N^{*}$ will never fall below 5.83 and never exceed 9.98.

Again, from Table 1, the range of total expected cost per unit time at $\alpha=1$ is $[46.26,47.53]$, which are most possible values of the total expected cost per unit time. Further the range of the total expected cost at $\alpha=0$ is [31.18,44.38], which indicates that the expected cost will never fall below 31.18 and exceed 44.38

If the classical method is used with $\lambda=3.5, \beta=11.5, \mu=9.5$, $\theta=4.5, \alpha=0.3, \gamma=4.5, \mathrm{C}_{\mathrm{h}}=6, \mathrm{C}_{\mathrm{o}}=15, C_{m}=180, \mathrm{C}_{\mathrm{s}}=275, C_{b}$ $=65$ and $\mathrm{C}_{\mathrm{r}}=45$, the optimal threshold $N^{*}=9.39$ and the minimum total expected cost of service per unit time is 44.07 . The values of $N^{*}$ and minimum total expected cost obtained for the crisp values of system parameters and cost elements falls in this range. This shows the validity of the numerical solutions obtained for the total expected cost and the threshold $N^{*}$.

\section{CONCLUSIONS}

This article applies the ideas of $\alpha$-cut and Zadeh's extension principle to an N-policy controlled Markovian queue with an unreliable server to obtain the lower and upper bound for the optimal threshold $\mathrm{N}^{*}$ as well as the minimal total expected cost per unit time. When the classical queues with unreliable server can be extended to queueing models with fuzzy parameters, the fuzzy queue can be represented more accurately by using the proposed approach and will have realistic applications. The results obtained from the analysis for the queueing model studied in this paper are useful and significant for system designers and practitioners in designing production systems and communication systems. The fuzzy approach presented in this paper can be extended to study other crisp two-phase, N-policy queues with batch arrival, server breakdowns and delayed repair.

\section{ACKNOWLEDGMENT}

The authors express their sincere and heartful thanks to the referee for their suggestions. The suggestions by the referee had substantially increased the quality of the paper in all dimensions. Further, the authors are thankful to the managements of Koneru Lakshmaiah Education Foundation (Deemed to be university), Vignans Foundation for Science Technology \& Research and Dhanekula Institute of Engineering and Technology for the constant encouragement given to pursue this research study. But for their encouragement and inspiration, all our ideas could not have had taken the present form of submitting as a research paper.

\section{REFERENCES}

[1] Yadin, M., Naor, P. (1963). Queueing systems with a removable service station. Operational Research Quarterly, 14(4): 391-405. https://doi.org/10.2307/3006802

[2] Teghem Jr., J. (1987). Optimal control of a removable server in an M/G/1 queue with finite capacity. European Journal of Operational Research, 31(3): 358-367. https://doi.org/10.1016/0377-2217(87)90045-2

[3] Lee, H.W., Srinivasan, M.M. (1989). Control policies for the $\mathrm{M}^{\mathrm{X}} / \mathrm{G} / 1$ queueing system. Management Science, 35(6): 708-721. https://doi.org/10.1287/mnsc.35.6.708

[4] Medhi, J., Templeton, J.G.C. (1992). A Poisson input queue under N-Policy with a general startup time. Computers \& Operations Research, 19(1): 35-41. https://doi.org/10.1016/0305-0548(92)90057-C

[5] Takagi, H. (1993). M/G/1/K queues with N-policy and setup times. Queueing Systems, 14(1-2): 79-98. https://doi.org/10.1007/BF01153527

[6] Wang, K.H., Hsiih, W.F. (1995). Optimal control of a removable and non-reliable server in a Markovian queueing system with finite capacity. Microelectronics and $\quad$ Reliability, 35(2): 189-196. https://doi.org/10.1016/0026-2714(95)90085-5

[7] Lee, H.W., Park, J.O. (1997). Optimal strategy in NPolicy production system with early set-up. Journal of Operational Research Society, 48(3): 306-313. https://doi.org/10.1038/sj.jors.2600354

[8] Hur, S., Paik, S.J. (1997). The effect of different arrival rates on the $\mathrm{M} / \mathrm{G} / 1$ with server setup. Applied Mathematical Modelling, 23(4): 289-299. https://doi.org/10.1016/S0307-904X(98)10088-4

[9] Ke, J.C. (2003). The analysis of a general input queue with N-policy and exponential vacations. Queueing Systems, $\quad 45(2)$ :

135-160. https://doi.org/10.1023/a:1026045706255

[10] Tadj, L., Ke, J.C. (2003). Control policy of a hysteretic queueing system. Mathematical Methods of Operations Research, 57(3): 367-376. https://doi.org/10.1007/s001860200264

[11] Wang, K.H. (2003). Optimal control of a removable and non-reliable server in an $\mathrm{M} / \mathrm{M} / 1$ queueing system with an exponential startup time. Mathematical Methods of 
Operations Research, 58(1):

29-39.

https://doi.org/10.1007/s001860300275

[12] Wang, K.H., Kao, H.T., Chen, G. (2004). Optimal Management of a removable and non-reliable server in an infinite and a finite $\mathrm{M} / \mathrm{H}_{\mathrm{k}} / 1$ queueing system. QTQM, 1(2): 325-339. https://doi.org/10.1080/16843703.2004.11673079

[13] Tadj, L., Choudhury, G. (2005). Optimal design and control of queues. TOP, 13(2): 359-412. https://doi.org/10.1007/bf02579061

[14] Tadj, L., Choudhury, G., Tadj, C. (2006). A quorum queueing system with random setup time under N-policy and with Bernoulli vacation schedule. QTQM, 3(2): 145160. https://doi.org/10.1080/16843703.2006.11673106

[15] Wang, K.H., Wang, T.Y., Pearn, L.W. (2007). Optimal control of the N-policy M/G/1 queueing system with server breakdown and general startup times. Applied Mathematical Modelling, 31(10): 2199-2212. https://doi.org/10.1016/j.apm.2006.08.016

[16] Kao, C., Li, C.C., Chen, S.P. (1999). Parametric programming to the analysis of fuzzy queues. Fuzzy sets and Systems, 107(1): 93-100. https://doi.org/10.1016/s0165-0114(97)00295-9

[17] Chen, S.P. (2004). Parametric nonlinear programming for fuzzy queues with finite capacity. European Journal of Operational Research, 157(2): 429-428. https://doi.org/10.1016/s0377-2217(03)00136-x

[18] Lin, C.H., Key, J.C. (2009). Optimal operating policy for a controllable queueing model with a fuzzy environment. Journal of Zhejiang University SCIENCE A, 10(2): 311318. https://doi.org/10.1631/jzus.a0820139

[19] Das, D., Baruah, H.K. (2015). Analysis of fuzzy queues: Parametric programming approach based on randomness-Fuzziness Consistency Principle. Journal of Process Management- New Technologies, 3(2): 1-7.

[20] Bagherinejad, J., Pishkenari, S.B. (2016). Analysis of FM/FM/C queueing system using fuzzy approach and parametric nonlinear programming, International Journal of Industrial and Systems Engineering, 23(2): 125-140. https://doi.org/10.1504/ijise.2016.076395

[21] Ashok Kumar, V. (2016). Parametric non-linear programming approach for N-policy queues with infinite capacity, Journal of Progressive Research in Mathematics, 10(2): 1470-1483.

[22] Varadarajan, R., Susmitha, R. (2018). Evaluation of performance measures of priority queues with fuzzy parameters using $\alpha$-cut approach. APRN Journal of Engineering and Applied Sciences, 13(7): 2636-2641.

[23] Kalpana, B., Anusheela, N. (2018). Analysis of fuzzy non-preemptive queues using Non-linear programming approach. International Journal of Mathematical Trends and Technology (IJMTT), 56(1): 71-80. https://doi.org/10.14445/22315373/ijmtt-v56p509

[24] George, T, Santhi, S., Selvakumari, K. (2020). Fuzzy queueing model with an unreliable server using Robust ranking method. PALARCH'S Journal of Archaeology of Egypt/Egyptology,17(7): 4835-4840. Retrieved from https://archives.palarch.nl/index.php/jae/article/view/26 02.

[25] Aarthi, A, Shanmugasundari, M., Saranya, V. (2020). A study on fuzzy queue with N-policy by triangular fuzzy numbers. European Journal of Molecular and Chemical Science, 7(3): 4544-4552.

[26] Vonodhini, A.F., Anitha, J. (2021). General service time distribution of fuzzy queue using parametric non-linear programming. Annals of the Romanian Society of Cell Biology, 25(6). Retrieved from https://www.annalsofrscb.ro/index.php/journal/article/vi ew/2822.

[27] Krishna, C.M., Lee, Y.H. (1990). A study of two- phase service. Operations Research Letters, 9(2): 91-97. https://doi.org/10.1016/0167-6377(90)90047-9

[28] Doshi, B.T. (1991). Analysis of a two-phase queueing system with general service times. Operations Research Letters, 10(5): 265-272. https://doi.org/10.1016/01676377(91)90012-E

[29] Kim, T.S., Chae, K.C. (1998). A two-phase queueing system with threshold. In IEEE GLOBECOM 1998 (Cat. NO. $\quad 98 \mathrm{CH} 36250), \quad$ 1: $502-507$. https://doi.org/10.1109/glocom.1998.775779

[30] Vasanta Kumar, V., Hari Prasad, B.V.S.N., Chandan, K. (2010). Optimal strategy analysis of an n-policy twophase $\mathrm{M} / \mathrm{E}_{\mathrm{k}} / 1$ queueing system with server break downs and gating. Applied Mathematical Sciences, 4(66): 32613272.

[31] Vasanta Kumar, V., Hari Prasad, B.V.S.N., Chandan, K. (2010). Optimal strategy analysis of an n-policy twophase $\mathrm{M}^{\mathrm{X}} / \mathrm{M} / 1$ gated queueing system with server startup and breakdowns. International Journal of Open Problems in Computer Science and Mathematics, 3(4): 563-584.

[32] Vemuri, V.K., Boppana, V.S.N.H.P., Kotagiri, C., Bethapudi, R.T. (2011). Optimal strategy analysis of an $\mathrm{N}$-policy two-phase $\mathrm{M}^{\mathrm{X}} / \mathrm{M} / 1$ queueing system with server startup and breakdowns. OPSEARCH, 48(2): 109122. https://doi.org/10.1007/s12597-011-0046-1

[33] Vasanta Kumar, V., Chandan, K., Ravi Teja, B., Hari Prasad, B.V.S.N. (2011). Optimal strategy analysis of an N-Policy two-phase $\mathrm{M}^{\mathrm{X}} / \mathrm{E}_{\mathrm{K}} / 1$ queueing system with server startup and break downs. An International Journal of Quality Technology and Quantitative Management, 8(3):

https://doi.org/10.1080/16843703.2011.11673260

[34] Vasanta Kumar, V., Chandan, K. (2007). Cost analysis of two-phase M/M/1 queueing system with N-policy and gating. Proc. A. P. Academy of Sciences, 11(3): 215-222. https://doi.org/10.1007/BF03398811

[35] Prasad, H. (2012). Optimal strategy analysis of twophase N-policy gated queueing systems with server startup and breakdowns. Ph.D. thesis, Acharya Nagarjuna University.

[36] Zadeh, L.A. (1978). Fuzzy sets as a basis for a theory of possibility. Fuzzy Sets and Systems, 1(1): 3-28. https://doi.org/10.1016/S0165-0114(99)80004-9
APPENDIX
$\%$ MATLAB code to solve the parametric nonlinear programming problems for
$\%$ the two-phase $\mathrm{M} / \mathrm{M} / 1$ gated queue with $\mathrm{N}$-policy and unreliable server
$\% \mathrm{X}$ and $\mathrm{Y}$ are the vectors representing the initial values of system parameters,
$\%$ cost elements and $\mathrm{N}$-value
$\% x(1)$-Arrival rate; $x(2)$-Individual Service rate; $x(3)$-Bathch service rate
$\% x(4)-S t a r t u p$ rate; $x(5)$-Breakdown rate; $\mathrm{x}(6)$-Repair rate; $\mathrm{x}(7)$-Holding cost 
$\% x(8)-$ Running cost; $\mathrm{x}(9)-$ Startup cost; $\mathrm{x}(10)$ Setup cost; $\mathrm{x}(11)-$ Breakdown cost

$\% x(12)$-Reward; fn and fny :function to define P000;

$\%$ e0,e1,e2,e3,e4,ec row,e0y,e1y,e2y,e3y,e4y,ecy are the functions to define

$\%$ the respective expressions

\%lng-Expected system length

clc

syms al aeq beq lb ub

$\mathrm{x}=[1,1,1,1,1,1,1,1,1,1,1,1,1] ; \mathrm{y}=[1,1,1,1,1,1,1,1,1,1,1,1,1]$;

$\mathrm{fn}=@(\mathrm{x})(1-(\mathrm{x}(1) / \mathrm{x}(2)) *(1+\mathrm{x}(5) / \mathrm{x}(6))-$

$\mathrm{x}(1) / \mathrm{x}(3)) * \mathrm{x}(4) /(\mathrm{x}(1)+\mathrm{x}(13) * \mathrm{x}(4))$;

$\mathrm{e} 0=@(\mathrm{x}) \mathrm{x}(13) / \mathrm{x}(1)$;

e1=@(x) 1/x(4);

$\mathrm{e} 2=@(\mathrm{x}) 1 /(\mathrm{x}(3) * \mathrm{fn}(\mathrm{x}))$;

$\mathrm{e} 3=@(\mathrm{x}) \mathrm{x}(1) / \mathrm{x}(2)$

$\mathrm{e} 4=@(\mathrm{x})(\mathrm{x}(1) / \mathrm{x}(2)) * \mathrm{x}(5) / \mathrm{x}(6)$;

ec= @(x) $1 /(\mathrm{x}(1) * \mathrm{fn}(\mathrm{x}))$;

row $1=@(\mathrm{x}) \mathrm{x}(1) / \mathrm{x}(2) *(1+\mathrm{x}(5) / \mathrm{x}(6))$;

$\mathrm{t} 1=\mathrm{x}(1) /(\mathrm{x}(3) *(1-\operatorname{row} 1(\mathrm{x})))+\operatorname{row} 1(\mathrm{x}) /(1-\operatorname{row} 1(\mathrm{x}))$;

$\mathrm{t} 2=\mathrm{x}(1) * \mathrm{x}(5) *(\mathrm{x}(1) / \mathrm{x}(2)) /\left(\mathrm{x}(6)^{\wedge} 2 *(1-\operatorname{row} 1(\mathrm{x}))\right)$;

$\mathrm{t} 3=(\mathrm{x}(1) / \mathrm{x}(3))^{\wedge} 2 * \operatorname{row} 1(\mathrm{x}) /(1-\operatorname{row} 1(\mathrm{x}))$;

$\mathrm{t} 4=\mathrm{x}(13) *(\mathrm{x}(13)-1) * \mathrm{fn}(\mathrm{x}) /(2 *(1-\operatorname{row} 1(\mathrm{x})))$;

$\mathrm{t} 5=\mathrm{x}(1) *(\mathrm{x}(1)+\mathrm{x}(13) * \mathrm{x}(4)) * \mathrm{fn}(\mathrm{x}) /\left(\mathrm{x}(4)^{\wedge} 2 *(1-\operatorname{row} 1(\mathrm{x}))\right)$;

$\operatorname{lng}=@(\mathrm{x}) \mathrm{t} 1+\mathrm{t} 2+\mathrm{t} 3+\mathrm{t} 4+\mathrm{t} 5$;

fun1=@(x)

$\mathrm{x}(7) * \operatorname{lng}(\mathrm{x})+\mathrm{x}(8) *(\mathrm{e} 1(\mathrm{x})+\mathrm{e} 2(\mathrm{x})) / \mathrm{ec}(\mathrm{x})+\mathrm{x}(9) * \mathrm{e} 1(\mathrm{x}) / \mathrm{ec}(\mathrm{x}) \ldots$ $+\mathrm{x}(11) * \mathrm{e} 4(\mathrm{x}) / \mathrm{ec}(\mathrm{x})+\mathrm{x}(10) / \mathrm{ec}(\mathrm{x})-\mathrm{x}(12) * \mathrm{e} 0(\mathrm{x}) / \mathrm{ec}(\mathrm{x})$;

nonlincon1=@cdefhpmm1;

nonlincon2=@cdefhp1mm1;

fny=@(y) (1-

$((\mathrm{y}(1) / \mathrm{y}(2)) *(1+\mathrm{y}(5) / \mathrm{y}(6))+\mathrm{y}(1) / \mathrm{y}(3)) * \mathrm{y}(4) /(\mathrm{y}(1)+\mathrm{y}(13) * \mathrm{y}(4))$

)

$\mathrm{e} 0 \mathrm{y}=@(\mathrm{y}) \mathrm{y}(13) / \mathrm{y}(1) ;$

$\mathrm{e} 1 \mathrm{y}=@(\mathrm{y}) 1 / \mathrm{y}(4)$;

$\mathrm{e} 2 \mathrm{y}=@(\mathrm{y}) 1 /(\mathrm{y}(3) * \mathrm{fny}(\mathrm{y}))$;

$\mathrm{e} 3 \mathrm{y}=@(\mathrm{y}) \mathrm{y}(1) / \mathrm{y}(2)$;

$\mathrm{e} 4 \mathrm{y}=@(\mathrm{y}) \mathrm{y}(1) / \mathrm{y}(2) * \mathrm{y}(5) / \mathrm{y}(6)$

ecy $=@(y) 1 /(y(1) * f n y(y))$

row $1 \mathrm{y}=@(\mathrm{y}) \mathrm{y}(1) / \mathrm{y}(2) *(1+\mathrm{y}(5) / \mathrm{y}(6))$;

$\mathrm{t} 1 \mathrm{y}=\mathrm{y}(1) /(\mathrm{y}(3) *(1-\operatorname{row} 1 \mathrm{y}(\mathrm{y})))+\operatorname{row} 1 \mathrm{y}(\mathrm{y}) /(1-\operatorname{row} 1 \mathrm{y}(\mathrm{y}))$;

$\mathrm{t} 2 \mathrm{y}=\mathrm{y}(1)^{*} \mathrm{y}(5) *(\mathrm{y}(1) / \mathrm{y}(2)) /\left(\mathrm{y}(6)^{\wedge} 2 *(1-\operatorname{row} 1 \mathrm{y}(\mathrm{y}))\right)$;

$\mathrm{t} 3 \mathrm{y}=(\mathrm{y}(1) / \mathrm{y}(3))^{\wedge} 2 *$ row $1 \mathrm{y}(\mathrm{y}) /(1-\operatorname{row} 1 \mathrm{y}(\mathrm{y}))$;

$\mathrm{t} 4 \mathrm{y}=\mathrm{y}(13) *(\mathrm{y}(13)-1) *$ fny $(\mathrm{y}) /(2 *(1-\operatorname{row} 1 \mathrm{y}(\mathrm{y})))$;

$\mathrm{t} 5 \mathrm{y}=\mathrm{y}(1) *(\mathrm{y}(1)+\mathrm{y}(13) * \mathrm{y}(4)) *$ fny $(\mathrm{y}) /\left(\mathrm{y}(4)^{\wedge} 2 *(1-\operatorname{row} 1 \mathrm{y}(\mathrm{y}))\right)$;

$\operatorname{lng} \mathrm{y}=@(\mathrm{y}) \mathrm{t} 1 \mathrm{y}+\mathrm{t} 2 \mathrm{y}+\mathrm{t} 3 \mathrm{y}+\mathrm{t} 4 \mathrm{y}+\mathrm{t} 5 \mathrm{y}$;

fun2=@(y)-

$(\mathrm{y}(7) * \operatorname{lngy}(\mathrm{y})+\mathrm{y}(8) *(\mathrm{e} 1 \mathrm{y}(\mathrm{y})+\mathrm{e} 2 \mathrm{y}(\mathrm{y})) / \mathrm{ecy}(\mathrm{y})+\mathrm{y}(9) * \mathrm{e} 1 \mathrm{y}(\mathrm{y}) / \mathrm{ecy}$ (y)...

$+\mathrm{y}(11) * \mathrm{e} 4 \mathrm{y}(\mathrm{y}) / \mathrm{ecy}(\mathrm{y})+\mathrm{y}(10) / \mathrm{ecy}(\mathrm{y})-\mathrm{y}(12) * \mathrm{e} 0 \mathrm{y}(\mathrm{y}) / \mathrm{ecy}(\mathrm{y}))$;

$\%$ al- alpha value; $\mathrm{x} 10$ : vector represnting assumed values of \%system parametersvalues

for $\mathrm{al}=0.0: 0.1: 1.0$

$\mathrm{x} 10=[2,8,10,3,0.2,3,5,10,100,200,50,20,1]$;

$\mathrm{a}=[] ; \mathrm{b}=[] ; \mathrm{aeq}=[] ; \mathrm{beq}=[]$;

$\mathrm{lb}=[\operatorname{double}(\mathrm{vpa}(\mathrm{al}+2)), \operatorname{double}(\mathrm{vpa}(\mathrm{al}+8)), \operatorname{double}(\mathrm{vpa}(\mathrm{al}+10))$ ,double $(\operatorname{vpa}(\mathrm{al}+3)), \ldots$

double $(v p a(a l * 0.1+0.2))$, double $(v p a(a l+3))$, double $(v p a(a l+5)$ ),double(vpa(al+10)), double(vpa(al*10+100)), ...

double(vpa $(\mathrm{al} * 50+200))$, double(vpa $(\mathrm{al} * 5+50))$, double(vpa(al $* 5+20)), 3]$;

$\mathrm{ub}=[$ double $(\mathrm{vpa}(5-\mathrm{al}))$, double(vpa(11-al)), double(vpa(13-

al)), double(vpa(6-al) $), \ldots$

double(vpa(0.5-al*0.1)), double(vpa(6-al)), double(vpa(8-

al)), double(vpa(13-al)), double(vpa(130-al*10)),...

double(vpa(350-al*50)), double(vpa(65-

al*5)), double(vpa(35-al*5)),inf];

[x1,fval] $=$ fmincon(fun 1,x10,a,b,aeq,beq,lb,ub,nonlincon1) x20 $=[2,8,10,3,0.2,3,5,10,100,200,50,20, x 1(13)]$;

$\mathrm{lb}=[\operatorname{double}(\mathrm{vpa}(\mathrm{al}+2)), \operatorname{double}(\mathrm{vpa}(\mathrm{al}+8)), \operatorname{double}(\mathrm{vpa}(\mathrm{al}+10))$ ,double $(\operatorname{vpa}(\mathrm{al}+3)), \ldots$

double(vpa $(\mathrm{al} * 0.1+0.2))$,double $(\mathrm{vpa}(\mathrm{al}+3))$,double(vpa(al+5) ) ,double $(\mathrm{vpa}(\mathrm{al}+10))$,double $(\mathrm{vpa}(\mathrm{al} * 10+100)), \ldots$

double(vpa $\left.\left(\mathrm{al}^{*} 50+200\right)\right)$, double(vpa $\left.(\mathrm{al} * 5+50)\right)$, double(vpa(al $* 5+20)), \mathrm{x} 1(13)]$;

$\mathrm{ub}=[\operatorname{double}(\mathrm{vpa}(5-\mathrm{al}))$, double $(\mathrm{vpa}(11-\mathrm{al}))$, double $(\mathrm{vpa}(13-$

al)),double(vpa(6-al)),...

double(vpa(0.5-al*0.1)), double(vpa(6-al)), double(vpa(8-

al)), double(vpa(13-al)),double(vpa(130-al*10)),...

double(vpa(350-al*50)), double(vpa(65-

al*5)), double(vpa(35-al*5)),inf];

[x2]=fmincon(fun2,x20,a,b,aeq,beq,lb,ub,nonlincon2)

sigma $=\mathrm{x} 2(1) / \mathrm{x} 2(4)$

row $1=x 2(1) / \times 2(2) *(1+x 2(5) / x 2(6))$;

$\mathrm{n} 0=\operatorname{sqrt}(\operatorname{sigma} *(\operatorname{sigma}+1)+2 * \operatorname{sigma} *(1-$

row 1$) / x 2(7) *(x 2(9)+x 2(4) * x 2(10)+x 2(12)))$-sigma

$\mathrm{x} 2(13)=\mathrm{n} 0$;

fun2val=

$\mathrm{x} 2(7) * \operatorname{lngy}(\mathrm{x} 2)+\mathrm{x} 2(8) *(\mathrm{e} 1(\mathrm{x} 2)+\mathrm{e} 2(\mathrm{x} 2)) / \mathrm{ec}(\mathrm{x} 2)+\mathrm{x} 2(9) * \mathrm{e} 1(\mathrm{x} 2) /$ ec(x2)...

$+\mathrm{x} 2(11) * \mathrm{e} 4(\mathrm{x} 2) / \mathrm{ec}(\mathrm{x} 2)+\mathrm{x} 2(10) / \mathrm{ec}(\mathrm{x} 2)-\mathrm{x} 2(12) * \mathrm{e} 0(\mathrm{x} 2) / \mathrm{ec}(\mathrm{x} 2)$

end 